\title{
A finança digitalizada: informatização a serviço da mundialização financeira
}

\author{
Digitalized finance: informatization at the service of financial globalization
}

\author{
Edemilson Paraná(1) \\ (1) Universidade de Brasília
}

\begin{abstract}
Based on reports and financial data, in-depth interviews with information technology and financial system experts, representatives of the technology industry, investors and various actors in the Brazilian capital market, we draw in this article, a brief overview of Digitalized Finance, here understood as the technical-operational complex of circulation, accumulation and valuation of financial capital through automated technology resources, which accelerate the compression of spacetime flows in search of speculative gains. We seek, therefore, highlight the influence of Information and Communication Technologies (ICT) in the emergence and consolidation, especially from the 1980s, of a new globalized financial system operated in "real time" with intensive use of technological resources under the so-called finance-led regime of accumulation.
\end{abstract}

\section{Keywords}

financial capital; financialization; technology; informatization; globalization.

JEL Codes G15; G28; N26; O33; Z13.

\section{Resumo}

Com base em relatórios e dados financeiros, entrevistas em profundidade com especialistas em tecnologia da informação e sistema financeiro, representantes da indústria de tecnologia, investidores e distintos atores do mercado de capitais brasileiro, desenha-se, neste artigo, um breve panorama da Finança Digitalizada, aqui compreendida como o complexo técnico-operacional de gestão da circulação, acumulação e valorização de capital financeiro por meio de recursos tecnológicos automatizados, que aceleram a compressão dos fluxos espaço-tempo, em busca de ganhos especulativos. Busca-se, com isso, destacar a influência das Tecnologias da Informação e Comunicação (TIC) na emergência e consolidação, especialmente a partir da década de 1980, de um novo sistema financeiro mundializado, operado globalmente em "tempo real" com uso intensivo de recursos tecnológicos no âmbito do chamado regime de acumulação com dominância da valorização financeira.

\section{Palavras-chave}

capital financeiro; financeirização; tecnologia; informatização; mundialização.

Códigos JEL G15; G28; N26; O33; Z13. 


\section{Introdução}

"Lembra-te que tempo é dinheiro [...]"

Benjamin Franklin

Quando pensamos em uma bolsa de valores, a primeira imagem que geralmente vem à cabeça é um aglomerado de indivíduos portando aparelhos telefônicos e, ao mesmo tempo, gritando compulsivamente uns com os outros a respeito de ordens de compra e venda de ações, enquanto olham ansiosos, com expressões de euforia ou pânico, para monitores que passam de modo veloz informações e cotações de preços. Essa imagem, praticamente uma metonímia do capitalismo financeiro consagrada em coberturas fotográficas, televisivas e cinematográficas, quase não existe mais.

Em silêncio, o espaço físico das bolsas de valores, assim como os próprios indivíduos que antes gritavam no interior delas, tem pouca ou nenhuma função prática. As negociações ocorrem agora em potentes computadores e centros de dados operados 24 horas por dia em várias partes do mundo. No lugar dos antigos pregoeiros, compradores e vendedores de ações, estão físicos e astrofísicos, estatísticos, economistas formados nas melhores universidades do mundo e "mentes brilhantes" da matemática que desenham algoritmos e estratégias de negociação automatizadas para serem realizadas na velocidade de milissegundos por meio desses sistemas. O "espírito animal" dos mercados, conforme conhecida expressão de Keynes, livre de muitas de suas amarras materiais, corre hoje nas linhas de transmissão de fibra ótica de altíssima velocidade. Essa importante mudança ocorreu graças ao avanço das Tecnologias da Informação e da Comunicação (TIC) que se deu, sobretudo, a partir das últimas três décadas.

Desde o início década de 80, momento que marca a aceleração (Santos, 1992) do processo de transformação econômica estrutural definido como mundialização financeira (Chesnais, 1996), tal avanço do desenvolvimento tecnológico, no que se refere aos mercados de capitais, segue, basicamente, duas grandes tendências: i) o forte investimento na construção de sistemas de produção e circulação de informações em tempo real; e ii) a produção de meios capazes de viabilizar a realização de negociações simultâneas em diferentes mercados na maior velocidade possível.

Desde a antiguidade, o acesso a informações privilegiadas é um elemento fundamental na gestão do comércio e dos negócios. De alguma forma, 
a mesma fórmula, ainda que em outro nível de abstração, é verdade, pode ser aplicada na compreensão das razões que ativam o movimento de desenvolvimento técnico para operação nos mercados financeiros contemporâneos: antecipar, compilar e organizar informações prioritariamente e/ou antes dos concorrentes para obter ganhos econômicos a partir delas. Daí tais dimensões, informação e tempo serem fundamentalmente os eixos do veloz avanço na utilização das Tecnologias de Informação e Comunicação nos mercados financeiros.

Em sua conhecida obra A ética protestante e o "espírito" do capitalismo, Max Weber (2004) cita o sermão de Benjamin Franklin Necessary Hints to Those that Would Be Rich, escrito em 1736, como uma sonora voz daquilo que define como o "espírito" do capitalismo, o ethos utilitarista do moderno homem de negócios burguês. Vem desse texto a passagem "tempo é dinheiro", que ficaria marcada até os dias atuais como uma das mais conhecidas expressões da filosofia de vida pragmática sob a modernidade capitalista. Quase três séculos depois, poucas frases seriam mais didáticas na busca por explicar as lógicas e dinâmicas de funcionamento operacional do mercado financeiro em tempos de revolução informacional: o tempo, hoje fracionado em unidades impensáveis para Franklin e mesmo para Weber, significa muito dinheiro nos mercados.

Explorando a crescente flexibilização e liberação dos mercados financeiros em nível global, o avanço tecnológico acabou por impor-se como uma das principais fronteiras da competição entre os investidores, ciosos de ganhos crescentemente elevados no menor intervalo de tempo possível. A trajetória de tal avanço acabou por produzir um cenário em que negociações automatizadas de alta frequência (High Frequency Trading) são utilizadas como instrumento de especulação e arbitragem entre diferentes ativos nos mercados, em margens de mili, micro e até nano segundos, inflando o ganho dos investidores que melhor dispõem dessas tecnologias.

Tal cenário aponta para o que aqui denominamos "Finança Digitalizada". Este será um termo de uso recorrente ao longo deste artigo, que, espera-se, seja devidamente esclarecido ao longo do desdobramento do texto, com seus respectivos exemplos e contextualizações. De modo geral, definimos como Finança Digitalizada o complexo técnico-operacional de gestão da circulação, acumulação e valorização do capital financeiro por meio de recursos tecnológicos automatizados de ponta que aceleram a compressão dos fluxos espaço-tempo para exploração 
de ganhos financeiros por meio de especulação e arbitragem de papéis, moedas e outros ativos ${ }^{1}$.

Tal tendência para compressão do tempo - ou para descontar futuro no presente sem garantias de que seja realizado (Harvey, 1992) -guarda suas origens no próprio processo de configuração da dominância financeira na economia capitalista globalizada, na medida em que essa busca encontra novas formas de valorização para o capital. ${ }^{2}$ Mudanças institucionais e regulatórias levadas a cabo com especial ênfase a partir das décadas de 1970 e 1980, declaradamente voltadas para o aumento de competitividade, abriram caminho para uma estrutura de mercado favorável às negociações automatizadas. Isso porque o aumento em volume e velocidade dos negócios nos mercados, enfim liberalizados, forçou uma reconfiguração das estruturas de negociação. Em questão de poucos anos, o tempo utilizado no processamento de ofertas e de fechamentos de negócios nas bolsas de valores foi deixando de ser medido em minutos e segundos para ser contabilizado em frações de segundos. Trata-se de uma importante vantagem competitiva na mão dos atores que dispõem de tais recursos, e que encontram, dessa forma, por meio de ganhos crescentes, condições e incentivos para seguirem investindo em tal avanço. Assim, as tecnologias são superadas rapidamente umas pelas outras, em crescente nível de capacidade e sofisticação, impondo novos desafios e dificuldades para todas as categorias de investidores.

Ainda que a velha racionalidade de obtenção do maior ganho no menor tempo possível mantenha-se como o eixo compreensivo do modus operandi da Finança Digitalizada, a nova realidade é capaz de produzir instabilidades e problemas antes não observados. Daí a importância de ser bem compreendida; não há como explicar os mercados financeiros no início do século XXI, e o papel que ocupam na economia globalizada, sem adentrarmos na discussão a respeito de suas lógicas e dinâmicas de funcionamento operacional. Seja devido à crescente diminuição do fator humano em to-

1 Para uma discussão mais ampla e aprofundada sobre outros aspectos, consequências e condicionantes estruturais da Finança Digitalizada, ver: Paraná (2016).

2 Cabe atentar, nesse particular, para o processo descrito em Marx (2011, p. 445): "Assim, enquanto o capital, por um lado, tem de se empenhar para derrubar toda barreira local do intercâmbio, i.e., da troca, para conquistar toda a Terra como seu mercado, por outro, empenha-se para destruir o espaço por meio do tempo; i.e.; para reduzir a um mínimo o tempo que custa o movimento de um local a outro. Quanto mais desenvolvido o capital, quanto mais distendido, portanto, o mercado em que circula, tanto mais ele se empenha simultaneamente para uma maior expansão espacial do mercado e para uma maior destruição do espaço pelo tempo". 
das as etapas do processo de negociação nos mercados, seja por conta das novas possibilidades que abrem para a obtenção de ganhos literalmente virtuais (por meio de ativos, inovações financeiras e modelos de negociação antes inviáveis sem o auxílio de tais recursos tecnológicos), uma leitura direcionada à compreensão do estado da arte tecnológica dos mercados financeiros em nosso tempo pode amparar e trazer novos elementos à importante discussão a respeito da complexidade e sofisticação da economia capitalista (em suas múltiplas dimensões), bem como da crescente ampliação do fosso entre os mercados e as necessidades materiais mais prementes da vida social.

O estado da arte da Finança Digitalizada no início do século XXI está submetido, em última instância, à determinação econômica, é verdade que tal processo de desenvolvimento das TIC, no que se refere aos mercados financeiros, guarda uma série de outras influências, fatores de conformação e antecedentes lógico-cognitivos, como expressão de múltiplas práticas sociais que materializam-se no conteúdo de tais artefatos técnicos. Mapear alguns deles, então, tem importância capital.

Entre um dos mais importantes antecedentes lógico-cognitivos que viabilizaram a automatização das operações nos mercados está a sofisticação dos modelos matemáticos utilizados para precificação e previsão de performances de ativos financeiros na conformação de estratégias de negociação de papéis. Sabe-se que tais avanços tiveram um impacto importante na evolução da informática como um todo. Nos mercados financeiros, particularmente, os algoritmos de negociação (sequência lógica de parâmetros que executados levam a um dado objetivo) tornaram-se a base de sustentação cognitiva dos "robôs" de execução automática de ordens de compra e venda de ativos nos mercados.

Nas décadas de 1980 e 1990, matemáticos, economistas e investidores passaram a utilizar a teoria do caos e o cálculo estocástico em busca de padrões de ação e comportamento nos mercados financeiros. Combinando matemática, estatística, teoria dos jogos e décadas de dados comerciais, desenvolveram modelos complexos amparados em algoritmos poderosos para prever o comportamento dos mercados e, com isso, obter vantagens nas negociações. Desde então, mesmo após sucessivas crises, quando muitos foram colocados à prova, tais modelos são depositários de uma fervorosa confiança por parte dos agentes. Com o passar do tempo, tais modelos matemáticos sofisticaram-se na medida em que avançou a 
capacidade de processamento de dados e informações utilizadas em suas parametrizações. Nasce aí o Algorithmic Trading ou AlgoTrading (AT), a negociação automatizada por computador, que executa estratégias matematicamente orientadas de movimentos de compra e/ou venda para obtenção de ganhos financeiros nos mercados.

O High Frequency Trading (HFT), desdobramento direto desse avanço técnico, nada mais é do que uma forma de Algorithmic Trading que executa as ordens de sua estratégia em altíssima velocidade graças ao auxílio de tecnologias informacionais de ponta em múltiplas dimensões (software, hardware e infraestrutura de redes). Os mais sofisticados High Frequency Traders (HFTs) usam aprendizado automatizado e inteligência artificial para extrair ganhos por meio do conhecimento da estrutura de negociação dos mercados e informações sobre os fluxos de ordens dos investidores.

Com base em pesquisa de campo realizada no âmbito deste trabalho, ${ }^{3}$ foi possível verificar três grandes princípios gerais que norteiam a adoção desse modelo de negociação: i) economia de trabalho e diminuição de riscos do "fator humano" (emoções, subjetividade) via automação; ii) aumento nas velocidades e volumes de negociação para a obtenção de ganhos de escala por meio de pequenas arbitragens realizadas milhares de vezes em curtíssimos intervalos de tempo; e, simultaneamente; iii) obtenção de certa "onipresença" na operacionalização das negociações por meio do processamento de alto volume de dados e informações sobre ativos, preços, ofertas e negócios realizados nos mercados.

3 Ao todo foram 37 entrevistados (sendo 4 deles em mais de uma ocasião), ao longo de todo o ano de 2014 até maio de 2015, em Brasília (DF), em uma cidade não revelada por razão de proteção à fonte em MG, em uma cidade não revelada por razão de proteção à fonte em SP, São Paulo (SP) e Rio de Janeiro (RJ), que totalizaram mais de 55 horas de registro em áudio. Desses entrevistados, 9 são acadêmicos nas áreas de Sociologia, Economia, Ciência da Computação e Tecnologia da Informação e os demais 28 são profissionais do mercado financeiro, atuantes no momento de realização das entrevistas, em diversas áreas, entre eles diretores da BM\&FBovespa, representantes de corretoras de valores, bancos (ex-integrantes), instituições financeiras, empresas de tecnologia voltadas para o mercado financeiro, operadores, reguladores e outros profissionais da área. Como dados secundários, foram analisadas informações financeiras, contábeis, econômicas e macroeconômicas de diferentes fontes, entre as quais o Banco Central do Brasil (BCE), o Instituto Brasileiro de Geografia e Estatística (IBGE), a Comissão de Valores Mobiliários (CVM), além de consultorias internacionais e órgãos multilaterais, sendo a mais utilizada dessas fontes a própria BM\&FBovespa, em que puderam ser obtidos dados sobre volumes financeiros, perfil de investidores, balanços de companhias listadas em bolsa, entre outras. Para a obtenção, organização e configuração de um organograma de entrevistas e entrevistados, foi utilizada a técnica metodológica conhecida como "Bola de Neve" ou Snowball Sampling. Para mais informações sobre essa técnica de pesquisa, ver: Bickman e Rog (1997). 
Com base na exploração dessas possibilidades, os players do mercado desenham suas estratégias de negociação de curto, médio ou longo prazo, amparadas ou não em alta velocidade, a depender dos objetivos de ganho e perfil dos investimentos. Mesmo no que se refere aos HFTs, há várias estratégias distintas para sua aplicação e utilização nos mercados. Para além dessas especificações, por ora, no entanto, interessa mais a construção de um panorama geral a respeito de como funcionam e o que ensejam do ponto de vista do avanço tecnológico nos mercados.

Inovações de hardware e software para atender aos mercados globalizados de capitais, que observam enorme crescimento em seus volumes e volatilidades referentes a vários tipos de ativos em diferentes localidades, demandaram o desenvolvimento de estratégias sofisticadas de negociação eletrônica. Como parte desse contexto crescentemente complexo, os investidores apoiam-se principalmente em soluções de conectividade para acessarem, na menor diferença de tempo possível, oportunidades de ganho em distintas partes do globo. A análise e exploração quase simultânea dessas diferenças de liquidez são alguns dos vários desafios colocados para investidores de todos os tipos. Entre esses participantes do mercado, a habilidade de acelerar processos, analisar e reagir a essa verdadeira avalanche de dados é uma componente fundamental na composição de sua vantagem competitiva. Quaisquer que sejam os interesses, objetivos e natureza dos investidores, a velocidade passa a ser um fator preponderante em sua atuação. Tal fator acaba por ser determinante no movimento de avanço das referidas tecnologias: a busca pela chamada "baixa latência".

Latência é um termo técnico muito utilizado na operação cotidiana da Finança Digitalizada. Apesar de ser definida de diferentes formas em diferentes contextos pelos agentes do mercado, pode ser compreendida, de modo geral, como o período de tempo em que um pacote de informações leva para percorrer a distância entre sua origem e destino, ou seja, a quantidade de tempo que um sistema "espera" para receber a informação. Assim, minimizar cada vez mais a latência significa diminuir tempos e/ou distâncias na circulação de dados e informações, objetivo absolutamente determinante na implementação de tecnologias de operação e negociação nos mercados financeiros, de modo a ampliar significativamente as operações de compra e venda, reduzindo o tempo entre elas.

Mas há limites técnicos para o aumento de velocidade no mundo das negociações eletrônicas. Por definição, o limite teórico máximo de velocida- 
de de trânsito de informação em uma rede é a velocidade da luz, valor que está longe da realidade de qualquer rede atualmente, mesmo as mais rápidas. Isso porque há latência inerente, entre outras razões, à composição dos materiais do hardware utilizado, assim como um intervalo de tempo necessário para o processamento do software. É na superação dessa fronteira que trabalham os grandes atores. Assim que um dos participantes do mercado ultrapassa certo limite de velocidade, a competição pelos ganhos advindos dessa vantagem determina que os demais o alcancem. Desse modo, o ciclo competitivo nos mercados digitalizados, ancorado, sobremaneira, no avanço tecnológico, nunca se completa, e as constantes mudanças que observamos nos mercados de capitais exigem cada vez mais avanços tecnológicos.

De modo adicional, o crescimento dos volumes e números de negócios realizados amplia a produção de mais dados. Mesmo os próprios avanços técnicos nesse campo ensejam a captação de outras, e antes inexploradas, informações, que forçam ainda mais a capacidade dos sistemas. Estes, por seu turno, necessitam de cada vez mais performance, num crescente nível de evolução, o qual, em média, dobra a cada dois anos, conforme nos relatou o entrevistado $\mathrm{A}^{4}$, um alto executivo da área de tecnologia da BM\&FBovespa que há anos acompanha a evolução desse mercado. ${ }^{5}$

A tão comentada (e temida) latência - que, apesar de usualmente medida em milissegundos, é relativa de acordo com diferentes tipos de operadores e estratégias de negociação a necessitar de mais ou menos velocidade para sua execução - tem várias origens. Dessa forma, a busca pelo encurtamento do tempo na trajetória de dados se dá em diferentes aspectos. As três principais áreas apontadas por vários especialistas e integrantes do mercado, como as origens fundamentais da latência ou as dimensões tecnológicas em que as inovações buscam diminuí-la, são: i) a rede por onde passam as mensagens; ii) os programas e as aplicações que as operam; iii) ou ainda os hardwares que processam tais informações.

Sem dispor de certa capacidade para mensurar tais falhas, que também exige por si só outros recursos tecnológicos, torna-se difícil discernir se a "baixa" velocidade é causada por uma rede que não tem largura de banda

4 Informação obtida em entrevista concedida por Entrevistado A, executivo da área de tecnologia da BM\&FBovespa, ao pesquisador em 09/06/2014, na cidade de São Paulo. 1 arquivo .mpeg4 (64min25seg).

5 Tal observação se encaixa no enunciado da Lei de Moore, que prevê a tendência do número de transistores de circuitos integrados dobrar a cada dois anos. Para mais informações, ver: Brock (2006). 
suficiente, por uma aplicação mal programada ou por falta de potência nos servidores que processam as informações. Assim, sob o ponto de vista tecnológico - que cada vez mais se estende para os negócios como um todo nos mercados, a negociação alcançou um patamar em que toda a infraestrutura precisa ser monitorada para que sejam encontrados e eliminados quaisquer traços de lentidão. A depender de como um investidor explora seus ganhos, apostando em alta velocidade de execução, deve estar atento a essas três dimensões como partes integrantes de um mesmo complexo.

Tal quadro levou alguns consultores de tecnologia para o mercado financeiro - como Larry Tabb, um dos mais conhecidos no mercado estadunidense - a discutir a viabilidade de precificação do próprio tempo na operação dos mercados. Ainda que o exercício que realiza no trabalho The Value of a Millisecond, de 2008, seja em si pouco amparado do ponto de vista teórico, o relatório é elucidativo ao apresentar de maneira didática os meandros técnicos da corrida aqui discutida, de tal modo, inclusive, que pôde, em linhas gerais, com algumas diferenças de intensidade e dimensão - sobretudo por conta de fatores institucionais e de distintos cenários econômicos - ser verificado na realidade do mercado de capitais brasileiro ${ }^{6}$, onde foi realizada a referida pesquisa que dá origem a este artigo. Com base em tais observações de campo, verifica-se que o autor é feliz quando aponta, por exemplo, que, devido à alta competitividade, os investidores do mercado financeiro geralmente estão entre os primeiros setores das economias a adotarem novas tecnologias informacionais de ponta.

Mas, como em qualquer tecnologia, uma coisa é clara: a inovação na aceleração de dados financeiros está chegando de todas as áreas de pesquisa de software e hardware. As instituições de serviços financeiros estão sempre dispostas a serem as primeiras a adotar novas tecnologias, uma vez que a competitividade afeta sua rentabilidade 7 . (Tabb, 2008, p.13).

O entrevistado $\mathrm{B},{ }^{8}$ representante de uma importante corretora de valores brasileira, ao comentar sobre a transformação que o novo modelo de negócios trouxe para sua empresa, afirmou: "não somos mais uma corretora, apenas.

6 Para uma sistematização da história recente, bem como dados atualizados sobre a digitalização do mercado de capitais no Brasil, ver: Paraná (2017).

7 But as in any technology, one thing is clear: the innovation in financial data acceleration is arriving from all areas of software and hardware research. Financial services institutions are always willing first adopters, as competitiveness affects profitability (Tabb, 2008, p.13).

8 Informação obtida em entrevista concedida por Entrevistado B, representante de uma corretora de valores, ao pesquisador em 09/06/2014, na cidade de São Paulo. 1 arquivo .mpeg4 (47min07seg). 
Mais do que uma gestora de investimentos que investe em modernização tecnológica, nos definimos hoje como uma empresa de tecnologia que negocia investimentos". Em consonância com seu depoimento, pode-se observar que entre as mais bem-sucedidas corretoras brasileiras, todas contam com setores inteiros, por vezes tão grandes quanto ou maiores que os demais, voltados à programação e à produção de soluções tecnológicas de nicho, desenvolvidas especialmente de acordo com as necessidades de seus clientes.

De fato, o novo cenário é especialmente desafiador para as corretoras de valores e seus profissionais. Muitas fecharam as portas e as que sobreviveram lutam para não ter o mesmo destino. A inexorável tendência de concentração dos mercados, observada de forma clara entre as corretoras, empurram-nas para uma completa reconfiguração de suas funções.

O modelo de negócios das bolsas de valores (e mesmo dos mercados alternativos, já que há países, como os Estados Unidos, onde papéis são negociados também fora das bolsas) depende, sobretudo, de sua capacidade de receber, agregar e fazer encontrar ordens de compra e venda de ativos. Um modelo tradicional, que ainda coexiste, de certa forma, com o novo que objetiva ser aqui descrito, confia a seres-humanos, especialistas, a missão de atrair compradores e vendedores para o mesmo espaço de negociação. Tais profissionais e empresas especializadas, as corretoras de valores, retiram seus ganhos basicamente da comissão ou corretagem que cobram por esse trabalho. A elas cabe, ainda, aconselhar e auxiliar, com base em seu conhecimento especializado, os clientes a respeito das melhores opções de investimentos.

No entanto, ancorado no crescente uso de negociação automática de alta velocidade, o novo modelo abandona, cada vez mais, avaliações qualitativas relativas ao comportamento do mercado, fatores macroeconômicos e saúde econômica das empresas listadas para combinar ordens de compra e venda utilizando basicamente duas variáveis (consideradas, de modo geral, mais imediatas e "objetivas"): tempo e preço. Se essa é uma realidade crescente, conforme se aprofunda o quadro de dominância financeira na economia mundial, o uso intensivo de tecnologia torna ainda mais premente tal lógica, sobretudo para os grandes investidores. Assim, corretores e as próprias bolsas são levados a reconfigurar seus modelos de negócio.

Nesse cenário, em que a crescente redução nos tempos de operação beneficia e atrai investidores, sobretudo os que negociam grandes volumes, a habilidade de receber e enviar rapidamente informações sobre o que se 
passa em seus livros de ofertas se tornou fundamental para a competitividade das próprias bolsas, que cobram, inclusive, por alguns desses dados (os mais estratificados). Em resposta, elas abraçam ainda mais o modelo de negociações eletrônicas, adotando avanços e soluções tecnológicas que as amparem de modo a atrair clientes/investidores com esse perfil. Assim, negócios de curto prazo, de alcance diário (intraday), voltados à especulação e arbitragem de papéis por meio do processamento em alta intensidade de dados de mercado, mais suscetíveis à competição em torno de baixa latência, ganham incentivos adicionais para tornarem-se dominantes. Dessa maneira, a busca crescente por ganhos rápidos e seguros de curto-prazo ativa o desenvolvimento de novas estratégias, ferramentas e soluções tecnológicas para a realização de negociações automatizadas em alta velocidade. Tais avanços, por sua vez, viabilizam e ampliam ainda mais tais oportunidades de ganho, incentivando que mais recursos sejam destinados ao avanço desse modelo de negociação.

$\mathrm{Na}$ batalha moderna dos filhos de Cronos contra seu poder implacável, que a tudo devora, resta ainda outra barreira: o espaço. Depois de aumentar a largura de banda, simplificar o código do programa e aumentar a capacidade de processamento de suas máquinas, há uma maneira adicional utilizada para reduzir a latência: diminuir a distância física ou o comprimento do caminho para a passagem de dados e informações. É a exploração do que os especialistas em TI usualmente denominam "topologia de rede", ou proximity, no jargão do mercado financeiro.

A maneira mais conhecida por meio da qual investidores buscam minimizar o caminho entre seus servidores de produção e os das bolsas e mercados, onde suas ordens são processadas e executadas, é fazendo com que as duas coisas estejam exatamente no mesmo local. Tal recurso, conhecido como Co-location, permite que os investidores coloquem unidades (hosts) de seus servidores dentro do próprio prédio da bolsa de valores (que naturalmente cobra por essa hospedagem), diminuindo assim a distância entre a ordem de negociação e sua execução no mercado. ${ }^{9}$

Tal segmento demanda e estimula, dessa forma, toda uma série de investimentos adicionais no mercado de baixa latência: servidores, prove-

9 Para um panorama do modo de funcionamento técnico do sistema de Co-location da bolsa brasileira em vídeo e texto, ver sítio da BM\&FBovespa na internet. Disponível em <http:// www.bmfbovespa.com.br/pt-br/servicos/solucoes-para-negociacao/acesso-direto-ao-mercado-dma/via-co-location.aspx?Idioma=pt-br>. Acesso em 14 jan. 2016. 
dores de conectividade, e meios capazes de viabilizar tecnicamente tais parcerias entre bolsas e mercados e sua nova classe de clientes privilegiados, ou seja, operadores de grande intensidade, que aceitam pagar altas quantias para estarem mais próximos fisicamente do centro de execuções, diminuindo assim latências relativas à comunicação externa, e lucrando, com a vantagem competitiva que essa diferença oferece em relação aos investidores que não dispõem de tal recurso. A concorrência, no entanto, não se encerra por aí. Mesmo nessa "classe especial" de investidores, entre eles, a corrida por diminuição de latência segue acontecendo nos outros aspectos anteriormente descritos.

Tal proximidade física (ou proximity) dos centros de execução e processamento de negócios nas bolsas e mercados não é explorada apenas por meio do serviço de Co-location. A corrida por baixa latência acaba se estendendo até mesmo por meio da instalação de infraestruturas de operação em prédios e localizações externas fisicamente próximas às bolsas, que, dessa maneira, veem subir consideravelmente o valor de imóveis e aluguéis em suas proximidades. $O$ mesmo se aplica aos materiais utilizados e trajetos de cabos de fibra ótica que compõem essas redes.

A utilização do recurso de Co-location já é considerável no Brasil. Desde setembro de 2010, quando foi adotado no mercado de ações brasileiro, o volume financeiro dos negócios realizados por meio desse recurso saltou de 0,2 para $12,5 \%$ do total e de 1,4 para $39,1 \%$ de todas as negociações realizadas no mercado acionário. A tendência de crescimento é contínua. De acordo com a informação do entrevistado $C^{10}$, executivo da BM\&FBovespa, o espaço reservado para a modalidade Co-location na bolsa brasileira já está completamente ocupado. Ainda segundo o executivo, a bolsa espera suprir a demanda crescente pela modalidade com um novo e maior centro de dados (Data Center), que está sendo construído na cidade de São Paulo. ${ }^{11}$

10 Informação obtida em entrevista concedida por Entrevistado C, executivo da BM\&FBovespa, ao pesquisador em 06/06/2014, na cidade de São Paulo. 2 arquivos .mpeg4 (122min19seg).

11 De acordo com o entrevistado D, proprietário de uma importante empresa de tecnologia para o mercado financeiro: "A UBS [corretora e banco de investimentos suíço], que comprou a Link [em 2010], a qual era uma das mais importantes corretoras brasileiras, é hoje a corretora que tem mais robôs em Co-location. Se não me engano, são cerca de 80 robôs deles dentro da bolsa. A maioria desses robôs que está na bolsa hoje é de grandes investidores estrangeiros: Credit Suisse, JP Morgan, Morgan Stanley, etc.". Entrevista concedida ao pesquisador em 14/05/2014, em uma cidade no Estado de Minas Gerais. 1 arquivo .mpeg4 (208min54seg). 
De modo simplificado, se na época em que o pregão era físico os operadores acotovelavam-se no espaço das bolsas e mercados em busca da realização dos melhores negócios, tal acotovelamento se dá atualmente entre computadores, na geografia ou topologia das redes do sistema de negociações. Dessa forma, o operador humano é substituído por um software (robô), ${ }^{12}$ e a diferença de tempo necessária para colocar um lance na frente é encurtada para milissegundos, que é justamente o tempo que um robô leva para tomar uma decisão, a partir dos padrões técnicos disponíveis.

Mas se a corrida está ancorada, principalmente, na diminuição do tempo, é importante notar que, apesar de todos os demais fatores cumprirem papel determinante, conforme anteriormente apontado, os softwares ${ }^{13}$ têm função absolutamente central na configuração nas estratégias de HFT mais competitivas. Assim, tomados como pontos de partida, os demais fatores passam a sustentar os softwares mais sofisticados de negociação em sua operação cotidiana. Isso porque sem um bom software de operação um computador potente ou um lugar privilegiado na geografia da rede tem pouca função efetiva.

Somando tudo isso, a informação não demonstra ter valor per se nos mercados. Em consonância com Stiglitz (2001), em seu paradigma da informação imperfeita, observa-se que a informação só pode ser explorada, enquanto tal, a partir de suas assimetrias, que existem em todas as economias. Tais assimetrias informacionais ou imperfeições, conforme apontou o autor, são fundamentais para compreender não só a economia de mercado, ${ }^{14}$ mas também a economia em seus aspectos políticos, com desdobramentos para todo o processo decisório das sociedades.

Adicionalmente, ancorado em uma leitura que busca desenhar pontes entre a semiologia e a cibernética na compreensão de sistemas sociotéc-

12 Para efeitos deste trabalho, o sentido da palavra robô, vinculada à dimensão de software, compreende a automatização de operações que envolvam varredura de um grande espaço de busca, e que, desse modo, requer heurística para aproveitar vantagens de uma busca inteligente, que de outra forma seria muito mais lenta na obtenção dos mesmos resultados. $O$ que faz um algoritmo ser um robô, portanto, é ter heurística, ou seja, regras empíricas para navegação e tomada de decisão em um certo espaço de busca de dados.

13 Em consonância com as formulações de Clark (2003), define-se software como uma prótese do pensamento, que potencializa as capacidades comunicativas e de raciocínio, dedução, tratamento e filtragem de dados para produção de informações na "mente" de certo receptor. 14 Nas palavras do entrevistado E, representante de uma grande empresa internacional de tecnologia para o mercado financeiro: "A coisa mais valiosa do mercado é a informação. $O$ mercado de capitais é feito de informação por essência (informação verbal)". Entrevista concedida ao pesquisador em 09/06/2014, na cidade de São Paulo. 1 arquivo .mpeg4 (74min42seg). 
nicos, como são, na atualidade, os mercados financeiros, pode-se concluir que a informação não existe, em si, nem mesmo como ente abstrato seja no ciberespaço, seja no mundo físico, mas apenas em um contexto comunicativo que envolve, pelo menos, um polo com capacidade cognitiva. Então, a informação pode ser compreendia como a capacidade que um fluxo de dados possui de transformar o estado de conhecimento de quem o recebe ou o transmite. No caso de quem transmite, tal mudança é indireta, de segunda ordem, vinculada à mudança de conhecimento daquele que recebe a informação. ${ }^{15}$

Assim, os dados (que não devem ser tomados como sinônimo de informação) são apenas agregados de símbolos em um contexto cognitivo qualquer, no qual tais símbolos podem representar, ou não, alguma informação para alguém. Para que essa representação ocorra, no entanto, é preciso haver um anteparo cognitivo que seja capaz de organizá-la, ou seja, transformá-la em uma linguagem. É essa linguagem que possibilitará que a informação produza a referida mudança no estado de conhecimento. Dessa forma, o que permite explorar economicamente tal processo não é propriamente a mudança do estado de conhecimento, mas tal mudança em um contexto de segunda ordem - "quem mais sabe o que eu sei". Dito de modo mais simples, dados são a matéria-prima da informação (explorada economicamente nos mercados).

Aí reside, pois, o ganho dos HFTs na exploração do tempo como vantagem competitiva, como instrumento de obtenção de informações privilegiadas. Mais uma vez, conforme aponta Stiglitz (2001), é a assimetria informacional que está a condicionar a exploração desse ganho (ou renda). Tal realidade é ampliada em um contexto de alto e crescente fluxo de informações, como é o dos mercados de capitais, que possibilita, dessa maneira, sempre novas assimetrias informacionais exploráveis. Aqueles que possuem os melhores canais para a obtenção de informações privilegiadas em menor tempo, e as melhores estratégias para explorar tais assimetrias, obtêm os maiores ganhos.

Nesse contexto, seja em sua obtenção de modo veloz, para operação automatizada nos mercados, seja em sua assimilação de modo organizado, inteligente e prático para a tomada de decisões de investimento, inclusive as automatizadas - nicho explorado por gigantes da comunicação 15 Para uma discussão a respeito da informação a partir uma abordagem semiológica, ver Teixeira Coelho Neto (1983, p. 119-195). 
como Bloomberg, Reuters e outras -, a informação obtida e operada de modo rápido e inteligente por softwares e suas respectivas infraestruturas é, certamente, o nó górdio da competição nos mercados de capitais contemporâneos.

\section{Os desdobramentos da digitalização nos mercados de capitais}

A corrida interminável pela obtenção de mais velocidade, na medida em que os mercados se digitalizam, está longe de apresentar sinais de queda. Nos últimos anos, a adoção de HFTs tem crescido consideravelmente e, em 2012, já estavam presentes em cerca de um terço de todas as negociações de ações na Europa e no Reino Unido, ${ }^{16}$ e algo em torno de $60 \%$ a $70 \%$ de todas as negociações com ações nos Estados Unidos. ${ }^{17}$

No Brasil, dados da BM\&FBovespa indicam que, em 2013, os HFTs já eram responsáveis por $15,6 \%$ de todo o volume financeiro com ações. Em 2010, esse percentual não passava de $5 \%$. Se contabilizados os demais AlgoTradings (ATs), deduzidos a partir dos dados a respeito das negociações realizadas por meio da utilização do sistema Co-location, cerca de $40 \%$ do total de negócios em bolsa no Brasil são realizados por robôs, em estratégias automatizadas.

O avanço desse processo tem produzido mudanças de grande magnitude na realidade dos mercados. Como se trata de assunto recente, no entanto, há pouca bibliografia disponível a respeito. A maioria dos trabalhos que discute o tema está restrito a relatórios de consultorias, instituições financeiras e órgãos de regulação, além de papers com abordagens técnicas de cunho econométrico, avaliando o impacto financeiro de sua adoção no retorno dos investimentos, sem discussões de fôlego a respeito da eletronificação dos mercados, em sentido amplo e, dessa forma, pouco conclusivos em relação aos propósitos deste trabalho.

16 Foresight: The Future of Computer Trading in Financial Markets. Final Project Report. The Government Office for Science, London, 2012. Disponível em <http://www.cftc.gov/ucm/ groups/public/@aboutcftc/documents/file/tacfuturecomputertrading1012.pdf>. Acesso em 14 jan. 2016.

17 TABB, L.; IATI, R.; SUSSMAN, A. US Equity High Frequency Trading: Strategies, Sizing and Market Structure. Tabb Group, 2009 (TABB Group Report). Disponível em <http://www. tabbgroup.com/PublicationDetail.aspx?PublicationID=505>. Acesso em 14 jan. 2016. 
De modo distinto, o livro de não-ficção Flash Boys (Lewis, 2014) oferece uma esclarecedora abordagem do assunto ao esmiuçar os bastidores desse novo modelo de negócios para bancos, grandes investidores e empresas de tecnologia.

A tese central de Lewis é a de que os mercados financeiros estão sendo fraudados por meio do uso de HFTs predatórios, de maneira que os poucos que dispõem dessas tecnologias ultravelozes de execução de negócios, em especial os grandes bancos de Wall Street, obtêm vultosos ganhos em detrimento dos demais investidores simplesmente explorando lapsos de tempo obtidos graças ao uso de supercomputadores e linhas de transmissão especiais dedicadas às bolsas e aos mercados.

O autor descreve uma dessas estratégias de algoritmos predatórios, em que a antecipação de milissegundos em relação aos demais investidores possibilita que programas identifiquem suas ordens, adicionem a mesma ordem na frente de tais investidores para, alguns milissegundos depois, sem que eles percebam, oferecê-las de volta aos mesmos, dessa vez a um novo preço. Dessa forma, sempre que o investidor enviar uma ordem, em compasso com o preço de mercado, ela não será executada, evaporando diante de um novo preço que é atualizado em frações de segundos, imperceptíveis para o olho humano. ${ }^{18} \mathrm{O}$ livro, que desenha um cenário marcado por manipulação de mercado e abuso de informação privilegiada por meio de recursos tecnológicos, gerou um intenso debate na opinião pública estadunidense, pressionando grandes investidores e reguladores - como a Security and Exchange Commission (SEC) e o Federal Bureau of Investigation (FBI) - a se pronunciarem e mesmo tomarem providências a respeito.

Os problemas advindos dessa lógica de funcionamento, no entanto, não se tornaram evidentes apenas agora. Falhas, erros e problemas de várias ordens nos mercados estão vinculados já há alguns anos com o modelo de negociações eletrônicas, em especial com AlgoTraders (ATs) e HFTs. Desde 2010, pelo menos, mas com antecedentes ainda mais longínquos, o mercado estadunidense tem passado por vários eventos adversos como

18 Operadores, investidores, programadores e até um matemático especializado em cálculos para o mercado financeiro, entrevistados para este trabalho, relataram que há inúmeras estratégias de algoritmos predatórios para além desta aqui descrita; desde a exploração do lapso de tempo por mecanismos de alta velocidade até plugins que forçam o atraso em ordens de concorrentes, etc. "A maioria paga para apanhar e perder, enquanto outros poucos para bater e ganhar. Assim funciona o jogo nos mercados com estratégias automatizadas", explicou o referido matemático. Informação obtida em entrevista concedida ao pesquisador em 07/06/2014, em uma cidade no Estado de São Paulo. 1 arquivo .mpeg4 (161min37seg). 
resultado de seu complexo, fragmentado e anarquicamente livre modelo institucional, em interação direta com falhas em recursos tecnológicos algoritmos de negociação com comportamentos inesperados, bugs em softwares ou hardwares congestionados. Em alguns casos, os problemas levam a panes ou a quedas bruscas nos índices e nos padrões de negociações dos mercados; produzindo os chamados Flash Crashes.

Foi o que aconteceu no dia 6 de maio de 2010 na Bolsa de Nova Iorque, uma das mais importantes do planeta, quando o índice Dow Jones Industrial Average (DJI) caiu cerca de 1000 pontos (9\%) em menos de 20 minutos devido a erros de operação com algoritmos de execução automática, que influenciaram as demais negociações, derrubando, assim, o mercado como um todo de forma assustadora. Como não haveria de ser diferente em uma realidade de mercados financeiros conectados, o problema teve desdobramentos imediatos no mundo todo, e os principais índices de ações passaram a despencar um após o outro. No Brasil, o índice Bovespa, que mede a performance das negociações em nossa bolsa, chegou a cair $6,38 \%$ no mesmo intervalo. ${ }^{19}$

O relatório The Hidden Alpha in Equity Trading (Bector et al., 2013), publicado pela consultoria de negócios Oliver Wyman, lista uma série de outros Flash Crashes que vêm ocorrendo nos últimos anos, denunciando, assim, o crescente risco sistêmico a que tem se submetido os mercados em busca de ganhos cada vez maiores em intervalos de tempo cada vez mais curtos. Há ainda uma série de outros eventos similares, em escala diminuída, também conhecidos Mini Flash Crashes (Golub et al., 2012), que ocorrem com certa frequência e, apesar de geralmente não chegarem a conhecimento público, produzem sérias instabilidades e riscos para os mercados.

Foi possível observar com mais clareza, sobretudo a partir de 2005, quando se intensifica o uso de negociações automatizadas por computadores, também devido a flexibilizações na regulação dos mercados estadunidenses, que abriram o cenário para sua expansão, mas há quem afirme que tais problemas têm origens mais longínquas.

19 No Brasil, conforme relatou o entrevistado $\mathrm{F}$ (entrevista concedida ao pesquisador em 04/06/2014, na cidade de São Paulo. Anotações de campo), representante de uma das principais empresas de tecnologia voltada ao mercado financeiro no país, há casos de robôs terem levado corretoras à falência por negociações que não podiam ser cobertas. Outros erros e gargalos de estrutura relacionados a operações automatizadas teriam levado a problemas na própria bolsa. Segundo o entrevistado D, outro empresário do ramo de tecnologia, em 2009 um robô do banco suíço de investimentos UBS gerou problemas em todo o sistema de negociação da bolsa e precisou ser desativado pelo banco. 
Ao discutir as mudanças induzidas nos mercados devido à adoção de sistemas de negociação automatizada, Smith (2010) retoma uma série de eventos ocorridos ao longo de várias décadas que, segundo o autor, teriam possibilitado e consolidado a penetração dos High Frequency Traders no mercado estadunidense até as dimensões atuais. Elencando importantes mudanças em esferas institucionais e tecnológicas no ambiente de negócios, sua linha do tempo inicia-se na década de 1960, quando é fundada a Nasdaq, a primeira bolsa a usar computadores para o processamento de dados, até 2010, quando ocorre o Flash Crash na Bolsa de Nova Iorque.

Voltando no tempo com ajuda dessa sistematização, é possível encontrar algumas evidências a respeito do modo como o crescimento e fortalecimento da supremacia dos mercados financeiros, como elemento de configuração da dominância financeira na economia mundial, está intimamente vinculado à implantação de avanços tecnológicos que possibilitaram a exploração de novas formas de ganho nos mercados, ampliando com isso suas instabilidades e riscos sistêmicos.

Figura 1 Linha do tempo das transformações técnico-operacionais nos mercados

\begin{tabular}{|c|c|c|c|c|c|}
\hline $1960 \mathrm{~s}$ & 1970 s & $1980 \mathrm{~s}$ & $1990 \mathrm{~s}$ & $2000 \mathrm{~s}$ & $2010 \mathrm{~s}$ \\
\hline $\begin{array}{l}10 \text { million daily } \\
\text { share volume } \\
\text { NYSE } \\
\text { 'paperwork' } \\
\text { crisis } \\
\text { 1963: SEC \& } \\
\text { NASD study } \\
\text { recommend } \\
\text { changes to OTC } \\
\text { market 'pink } \\
\text { sheets' } \\
\text { 1968: NASDAQ } \\
\text { founded - first } \\
\text { exchange to } \\
\text { heavily use } \\
\text { computers }\end{array}$ & $\begin{array}{l}\text { 1975: Reg NMS } \\
\text { 1976: NYSE DOT } \\
\text { electronic order } \\
\text { transmission } \\
\text { system } \\
\text { Late 1970s: First } \\
\text { physicists arrive } \\
\text { on Wall Street }\end{array}$ & $\begin{array}{l}\text { 1984: NYSE } \\
\text { Super-DOT order } \\
\text { transaction } \\
\text { system } \\
\text { Mid 1980s: Rise } \\
\text { of program } \\
\text { trading } \\
\text { 1987: Black } \\
\text { Monday crash; } \\
\text { partially blamed } \\
\text { on program } \\
\text { trading }\end{array}$ & $\begin{array}{l}\text { Dotcom boom } \\
\text { and huge } \\
\text { expansion of } \\
\text { NASDAQ } \\
\text { 1997: SEC Limit } \\
\text { Order Display } \\
\text { Rule - best } \\
\text { quotes must be } \\
\text { displayed } \\
\text { 1998: SEC } \\
\text { Regulation ATS } \\
\text { - beginnings of } \\
\text { huge growth in } \\
\text { ECN/ATS }\end{array}$ & $\begin{array}{l}\text { 2000: } \\
\text { Decimalization } \\
\text { of US equity } \\
\text { markets; NYSE } \\
\text { repeals rule } 390 \\
\text { 2005: Reg NMS } \\
\text { revision - HFT } \\
\text { goes prime time } \\
\text { 2006: NYSE/ } \\
\text { Archipelago/ } \\
\text { Euronext merger } \\
\text { 2007: CBSX } \\
\text { and Direct Edge } \\
\text { pioneer 'flash } \\
\text { orders'; August } \\
\text { 2007 begins } \\
\text { huge market } \\
\text { volatility } \\
\text { Late 2009: } \\
\text { Most ECNs } \\
\text { \& exchanges } \\
\text { suspend flash } \\
\text { orders }\end{array}$ & $\begin{array}{l}\text { May 6, 2010: } \\
\text { 'Flash crash' } \\
\text { affects multiple } \\
\text { stocks sending } \\
\text { the DJIA down } \\
\text { more than } 1,000 \\
\text { points at one } \\
\text { point }\end{array}$ \\
\hline
\end{tabular}

Fonte: Smith, R., 2010, p. 7. Disponível em: < http://arxiv.org/abs/1006.5490>. Acesso em 14 jan. 2016. 
Conforme apontado, o acelerado processo de digitalização dos mercados, nas últimas décadas, da qual a crescente utilização de ATs e HFTs nas negociações é, contemporaneamente, a maior expressão, aponta para cenários de fraude comercial (em que a supremacia tecnológica desenha um quadro no qual poucos ganham em detrimento de muitos que perdem de modo previsível) e instabilidades adicionais na operação dos mercados de capitais que, absortos pela arbitragem na escala de milissegundos, em um cenário de conectividade global, ampliam ainda mais seu risco sistêmico. Encorajados pela crença na neutralidade e infalibilidade técnica na superação dos erros advindos do "fator humano", ${ }^{20}$ operadores e investidores apostam em estratégias de negociação cada vez mais ousadas e arriscadas.

Adicionalmente, a ampliação de tal risco sistêmico está intimamente vinculada ao rápido crescimento da complexidade técnica e institucional dos mercados, que motiva o surgimento de inovações financeiras e a negociação de instrumentos que não seriam possíveis senão por meio dos mecanismos existentes em tal conjuntura de avanço tecnológico. Isso porque, em resposta ao desenvolvimento técnico, novos mecanismos, modos de negociação, regras de funcionamento e mesmo a existência de mercados paralelos crescem em número e complexidade, ativados sempre pela acirrada competição por ganhos cada vez mais expressivos. Somado a isso está o crescimento exponencial do volume de novas informações compiladas e processadas por tais sistemas de alta performance.

Tal complexidade enseja um convenientemente confuso modo de funcionamento dos sistemas, o qual poucos experts e operadores dominam por completo. Cresce, dessa forma, a opacidade dos mercados como elemento de controle e gestão de informações estratégicas na mão de elites cada vez mais fechadas de investidores, dificultando o acesso não só para

20 A diminuição acelerada do uso de seres humanos na operação dos mercados de capitais, uma tendência global, aponta para importantes mudanças institucionais e operativas na dinâmica de funcionamento dos mercados. Conforme relatou o entrevistado $\mathrm{H}$, apenas um grande banco internacional que opera no mercado de capitais brasileiro realiza cerca de 100 mil operações por dia controladas por apenas três operadores humanos. Para além dos pregoeiros (os negociadores que gritavam as opções de compra e venda de papéis nas bolsas), profissão praticamente extinta, é especialmente intrigante o caso das pequenas e médias corretoras de valores e seus profissionais, que lutam para sobreviver, buscando se reinventar em um contexto de acelerada transformação tecnológica, em que o próprio papel do corretor como mediador entre compradores e vendedores perde importância no modelo de negociações automatizadas. Entrevista concedida ao pesquisador em 06/05/2014, em Brasília (DF). 1 arquivo .mpeg4 (91min02seg). 
governos, reguladores e para a compreensão da sociedade, mas também para a operação de pequenos investidores que, à margem, ficam cada vez mais dependentes de grandes fundos, corretoras e instituições financeiras para gerir seus investimentos, na maioria das vezes de modo pouco transparente. Dessa forma, além de um recurso a mais a reforçar a marcha de concentração de ganhos nos mercados, a opacidade advinda da crescente complexidade amplia riscos de gestão e governança, na medida em que poucas pessoas conhecem de fato como funcionam os mercados financeiros digitalizados.

De modo adicional, o próprio crescimento dessa complexidade operativa abre novas oportunidades de negócios, uma vez que demanda ainda mais investimentos em tecnologias que possibilitem gerir de modo eficiente as operações financeiras em um ambiente de tal natureza. A própria gestão da complexidade torna-se, dessa forma, um negócio atrativo, especialmente para grandes empresas de ponta do setor tecnológico. Foi o que admitiu o entrevistado ${ }^{21}$, representante de uma grande empresa internacional de tecnologia que atua no mercado de capitais brasileiro. "Se o mercado fica mais complexo, você precisa de mais TI para descomplexar [sic], para facilitar; e daí eu entro no game. Para o meu nicho de mercado, por exemplo, é bom que cresça a complexidade e a consolidação do mercado em grupos cada vez maiores" (informação verbal).

Tal tendência para a complexidade crescente, que se objetiva de diferentes modos em variados mercados, nos diversos países e regiões, a partir de distintos contextos históricos, sociotécnicos e regulatórios, acabou por desenhar nos Estados Unidos, que concentra grande parte dos maiores e mais lucrativos mercados do planeta, uma estrutura de funcionamento anarquicamente descentralizada e opaca. Nela, diferentes mercados e bolsas recorrem a múltiplos e arriscados expedientes em busca de atrair investidores para seus espaços de negociação, ampliando, assim, os incentivos para o uso intensivo de tecnologia, na arbitragem de papéis entre tais ambientes de negociação, como os já mencionados ATs e HFTs, que nos EUA têm o maior índice de penetração do mundo. ${ }^{22}$

21 Entrevista concedida ao pesquisador em 09/06/2014, em São Paulo. 1 arquivo .mpeg4 (74min42seg).

22 A esse respeito, é elucidativo o panorama de funcionamento do mercado de capitais estadunidense traçado em Bector et al. (2013, p. 6). 


\section{Conclusões: a espiral de complexidade e o ciclo de operação da Finança Digitalizada}

A estrutura de funcionamento do mercado de capitais brasileiro é consideravelmente distinta dessa, sobretudo no que se refere à descentralização e regulação. A partir dos estudos realizados para este trabalho, no entanto, pode-se observar certo padrão nos diferentes mercados, mesmo em seus contextos particulares, no que se refere ao que aqui denominamos espiral de complexidade da Finança Digitalizada.

No bojo dessa formulação, as conclusões deste trabalho permitem sustentar que a ciranda de ampliação de riscos sistêmicos nos mercados financeiros não se dá apenas e meramente pela adoção de avanços tecnológicos, ainda que estes sejam fundamentais na objetivação desse cenário. Conforme se argumentou anteriormente, é da natureza dos sistemas sociotécnicos, entre as quais estão incluídas as bolsas de valores e os mercados financeiros, serem configurados a partir de múltiplas dimensões. Em consonância com esse ponto de vista, que aponta uma dinâmica complexa na relação entre ganhos financeiros e avanços tecnológicos crescentes, é possível descrever da seguinte forma uma espiral de crescente complexidade dos mercados: i) a busca por ganhos financeiros inexplorados demanda meios técnicos que possibilitem ultrapassar as atuais fronteiras materiais e técnicas à sua obtenção; ii) a adoção de tais tecnologias enseja a necessidade de novas configurações institucionais, modos e dinâmicas de operação sociotécnica nos mercados, que reconfiguram-se a partir das condições socioeconômicas presentes e dos embates políticos e sociais em torno de seus desdobramentos; e, por fim, iii) as possibilidades abertas a mais ganhos advindas do novo ambiente institucional e tecnológico incentivam, por meio da concorrência entre os investidores e do investimento em pesquisa e produção, o desenvolvimento e a implementação de novas soluções técnicas, que voltam a alimentar esse círculo de complexidade crescente (conforme quadro abaixo).

De modo mais objetivo, esse quadro aponta para uma tendência de fracionamento dos papéis negociados que, como elemento do mesmo processo que encurta tempos e distâncias, força a arbitragem e a especulação até o nível dos mínimos centavos. De modo complementar, enquanto tempos, distâncias e frações de papéis negociados diminuem, os volumes negociados crescem, ampliando o ganho financeiro agregado nos mercados. 


\section{Figura 2 A espiral de complexidade da finança digitalizada}

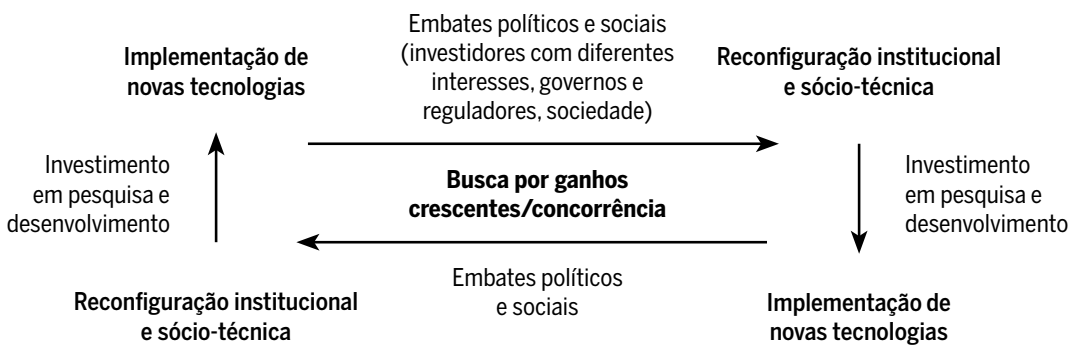

Fonte: elaboração própria.

No entanto, defensores dos modelos de negociação eletrônica argumentam que, enquanto turbulências e instabilidades podem ser mitigadas e combatidas por meio de outros recursos técnicos de governança e gestão de riscos (e é fato, inclusive, que há um aquecido mercado de soluções tecnológicas para investidores nesse particular), operações de alta intensidade são benéficas, na medida em que trazem liquidez, diminuindo as margens entre os papéis negociados (spreads), algo considerado saudável para os mercados. Argumenta-se ainda que o emprego de tais tecnologias possibilita derrubar custos de transação, além de oferecer mais eficiência e transparência aos sistemas de precificação.

$\mathrm{Na}$ contramão, em consonância com o que foi aqui problematizado, há inúmeros casos indicando que, ao invés de tornarem-se mais transparentes, os modelos de precificação, sobretudo quando ancorados em algoritmos complexos, tornam-se mais opacos porque mais confusos. Ademais, como qualquer modelo matemático, são passíveis de falhas em situações não previstas, ${ }^{23}$ conforme pôde ser observado em episódios vivenciados durante a grande crise financeira de 2008 (sendo esta considerada por certas teorias e modelos, até então, como uma impossibilidade matemática).

Se ATs e, sobretudo, HFTs trazem liquidez adicional aos mercados em momentos de aquecimento ou estabilidade, podem, em momentos de bai-

23 Um exemplo ironicamente elucidativo a esse respeito foi a falência do fundo de investimento Long-Term Capital Management, então presidido por Robert Merton e Myron Scholes, os quais dividiram o prêmio Nobel de Economia de 1997 pelo desenvolvimento de uma das principais ferramentas matemáticas utilizada no cálculo de derivativos até hoje, a fórmula Black-Scholes-Merton. Em 1998, um ano depois de seus gestores terem sido laureados, o fundo contabilizou perda de U\$ 4,6 bilhões e teve de fechar. É que seu complexo modelo matemático não levou em conta a chance de dois eventos extremos: a crise asiática de 1997 e a moratória do governo russo de 1998. 
xa, ampliar suas quedas de modo agressivo. No tocante ao controle de riscos, se é verdade que há sofisticados avanços técnicos em utilização, é patente que tais sistemas, tal qual a própria lógica da regulação per se, tendem a caminhar sempre um passo atrás de inovações financeiras que, na contramão, ampliam riscos, configurando um jogo bastante perigoso.

Tomados de modo descontextualizado em relação à economia em sentido amplo (incluída sua dimensão produtiva) e ignorando, desse modo, o processo de financeirização ${ }^{24}$ que tem desdobramentos em múltiplas dimensões sociais (Epstein, 2005), alguns desses argumentos de fato encontram correspondência, ainda que sejam motivo de intensos e inconclusivos debates, em perspectivas de ganhos de setores importantes do mercado. Corretos ou não, como pano de fundo de tais defesas, no entanto, está o fato de que seja para bolsas e mercados, que veem crescer suas possibilidades de ganhos com taxas e emolumentos a partir do aumento do número e volume de negociações realizadas em maior velocidade em seus ambientes, seja para grandes investidores e grandes players do setor de tecnologia para operação nos mercados, que conquistam crescentes percentuais dos mercados em suas mãos, o modelo é altamente lucrativo.

Conforme foi exposto, na medida em que há origens e desdobramentos sociais, o aumento substancial dos ganhos na esfera financeira não pode ser lido isoladamente, como um dado meramente contábil. Inter-relacionados com o funcionamento dos mercados financeiros estão, além da produção industrial e agropecuária, as dívidas soberanas dos países, sistemas de pensões e aposentadorias, investimentos pessoais e até o suprimento de alimentos na economia mundial..$^{25}$

24 Aqui entendido, primariamente, com base nas formulações de Chesnais (1996; 2002; 2005), como um processo de reordenação lógica geral da acumulação de capital em prol da valorização financeira, ou seja, de submissão do processo produtivo como um todo aos objetivos e modos de funcionamento desta. Tal processo pode ser explicado contemporaneamente pela i) autonomização da esfera financeira em relação à esfera da produção e ao controle do Estado; ii) pelo fetichismo próprio das formas de valorização do capital de natureza financeira (devido ao seu caráter altamente abstrato e fictício); e iii) pelo crescente poder dos "operadores financeiros" de traçar os contornos e os rumos da economia como um todo, ao decidirem quais agentes, de que países e que tipos de transação podem entrar ou não na mundialização financeira.

25 Estudo da Conferência das Nações Unidas sobre Comércio e Desenvolvimento (UNCTAD) demonstra como o grande envolvimento de investidores financeiros e suas inversões crescentes em commodities, negociadas como ativos financeiros, têm alterado o funcionamento do mercado de alimentos global. Ainda de acordo com o trabalho (Bicchetti; Maystre, 2012), o avanço da utilização de HFTs desenha um novo passo na financeirização do mercado de commodities, afetando, especialmente, os países mais pobres, que acabam tendo sua segurança alimentar condicionada à volatilidade dos movimentos de preços nos mercados da Finança Digitalizada. 
Para além de outros aspectos, é digno de nota o fato de que a colonização do mundo social pela dominância financeira atinge fundamentalmente a produção de conhecimento e informação. É o caso das grandes agências de notícias nacionais e internacionais, que se voltam cada vez mais para atender às necessidades de produção de informações em volumes e velocidades altíssimas para consumo dos mercados, financeirizando, dessa forma, até mesmo suas coberturas jornalísticas (Puliti, 2009). Para se ter uma dimensão do que isso significa, em 2014, dos 150 jornalistas que trabalhavam em uma grande agência de notícias brasileira, 120 estavam dedicados apenas à produção de informações em tempo real para o mercado de capitais. A razão de tal fato não poderia ser outra; o entrevistado $\mathrm{J}^{26}$, representante da agência em questão, relatou que o segmento de informações em tempo real para investidores é altamente lucrativo, com margem de retorno acima dos $30 \%$ de ganho, e já é responsável por quatro quintos de todo o faturamento de sua agência de notícias.

Assim, se o aumento dos lucros nos mercados financeiros nos últimos anos encontra respaldo na realidade, defendemos que tal realidade é, na verdade, produto de um amplo processo de reconfiguração da economia capitalista mundial, na conformação do chamado regime de acumulação com dominância da valorização financeira (Chesnais, 1996, 1998, 2005), que amplia a autonomia relativa para a acumulação de capital fictício ${ }^{27}$

26 Informação obtida em entrevista concedida ao pesquisador em 03/06/2014, em São Paulo (SP). 1 arquivo .mpeg4 (99min54seg).

27 O conceito de capital fictício, cunhado por Karl Marx, designa as formas de "capital bancário", descrito também pelo autor como "capital monetário", em oposição ao "capital real" aplicado em atividades produtivas e comerciais. É representado por títulos de propriedade sobre a riqueza futura (ações de empresas, duplicatas comerciais e/ou títulos públicos). Marx inclui ainda nessa categoria os depósitos criados pelos bancos em suas atividades de empréstimo, na medida em que eles não equivalem às reservas reais de moeda nos bancos e sim a um múltiplo delas, que dependem, dessa forma, de uma crença fictícia quanto aos retornos futuros de tais empréstimos. Nas palavras do autor: "Com o desenvolvimento do capital portador de juros e do sistema de crédito, todo capital parece duplicar e às vezes triplicar pelo modo diverso em que o mesmo capital ou simplesmente o mesmo título de dívida aparece, em diferentes mãos, sob diversas formas. A maior parte desse 'capital monetário' é puramente fictícia. Todos os depósitos, excetuado o fundo de reserva, são apenas créditos contra o banqueiro, mas nunca existem em depósito. À medida que servem para operações de compensação, funcionam como capital para os banqueiros, depois de estes os terem emprestado. Eles pagam entre si os direitos recíprocos sobre os depósitos não existentes mediante compensação mútua desses créditos... Assim como a mesma peça de dinheiro pode efetuar diferentes compras, conforme a velocidade de sua circulação, ela pode servir igualmente para realizar diferentes empréstimos, pois as compras fazem-na passar de uma mão para outra e o empréstimo é apenas uma transferência de uma mão para outra, que não é mediada por nenhuma compra." (Marx, 1988, p. 8-9). 
- aquele cuja valorização não passa diretamente pela compra de força de trabalho (Marx, 1988; Mollo, 2011). É este processo que possibilita que os players no mercado percebam, em chave fetichista, como ilimitada a valorização de seus ativos financeiros, ativada por novos instrumentos e inovações financeiras, e impulsionada por mecanismos de negociação automatizada, como os aqui descritos. Algo, como se sabe, intimamente vinculado ao desenvolvimento e aprofundamento de crises financeiras.

O avanço das Tecnologias da Informação e da Comunicação, particularmente no que se refere a sua adoção nos mercados de capitais, como parte que é desse processo mais amplo, não é o elemento que o funda, mas trata-se de uma dimensão crucial a tornar mais premente e imperativa tal lógica de dominância financeira, dado reforçar tais processos de autonomização relativa das formas fictícias de capital.

Se é verdade que o sistema financeiro internacional não existiria tal qual atualmente sem dispor dos recursos tecnológicos que ora explora, não há que se dizer que o avanço tecnológico é a causa fundamental de tais transformações econômicas, que seguem tendo como eixo conformador a busca pela acumulação e valorização de capital, à qual tais avanços servem. De toda sorte, tal dialética não aponta para uma submissão simplória do aspecto tecnológico ao econômico, mas, diversamente, para uma dinâmica de influência mútua - perpassada por várias dimensões sociais e políticas, capazes de dar múltiplos e variados contornos a esse processo - ainda que governada, em última instância, direta ou indiretamente, pela busca do ganho econômico como horizonte instrumental.

Amparado nas conclusões obtidas a partir desta pesquisa, sustenta-se que, dessa forma apresentada, tal dinâmica é perpassada por três dimensões em que atua a técnica na consolidação da dominância financeira em nosso tempo, desenhando o que passamos a denominar o ciclo de operação da Finança Digitalizada (conforme figura abaixo), a ser: i) enquanto trabalham na direção do encurtamento dos fluxos espaço-tempo, o avanço e a utilização das TIC viabilizam aumento do número e do volume de negócios nos mercados financeiros, ampliando a capacidade de acumulação de capital fictício, e aumentando, desse modo, os ganhos advindos de sua valorização; ii) devido a intensa velocidade e capacidade adaptativa de tais sistemas inteligentes, torna-se cada vez mais ingrato e custoso o trabalho de controle e regulação dos mercados, que estão sempre na fronteira tecnológica para ultrapassar barreiras técnicas, materiais e institucionais, 
em busca de acessar ganhos ainda inexplorados; e, por fim, iii) tal cenário reforça, em tempos de hegemonia do capital financeiro (e fictício), centralizações e concentrações de capitais e seus ganhos na mão de poucos investidores, em poucas praças financeiras mundiais, onde os ganhos tendem a se manter em cirandas ou "circuitos autorreferenciados" de valorização, sem alcançar suas imensas necessidades sociais. ${ }^{28}$

\section{Figura 3 Ciclo de operação da finança digitalizada}

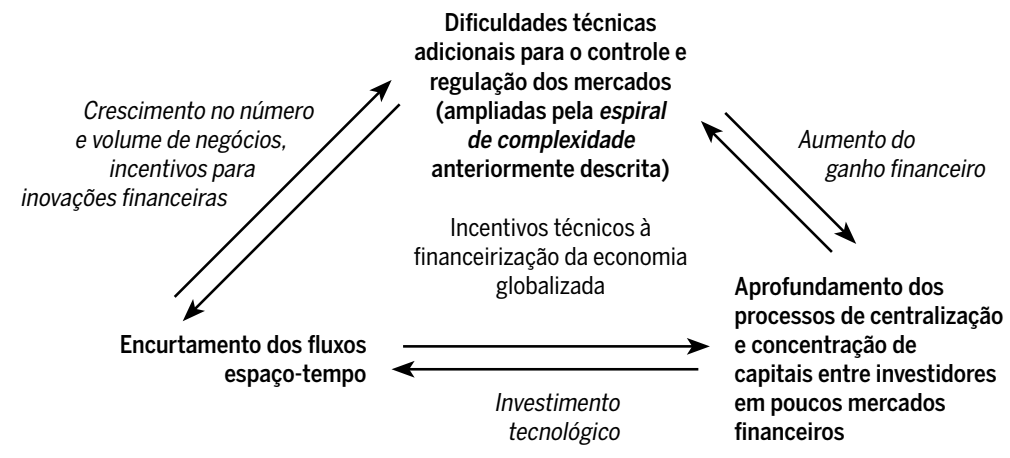

Fonte: elaboração própria.

Assim, a teórica função social conferida aos mercados financeiros nas economias capitalistas - como alocadores de necessidades econômicas, que possibilitam o encontro entre compradores e vendedores, tomadores e emprestadores de recursos de modo a viabilizar investimentos voltados à produção capaz de gerar emprego e renda (Minsky, 1986) - perde cada vez mais relevância, em detrimento de uma lógica crescentemente especulativa a drenar e concentrar os excedentes da produção social na esfera financeira, que passam a ser retroexplorados por meio de arbitragem na escala de microssegundos, viabilizada por avanços tecnológicos de ponta. Observa-se, dessa forma, reforçada a partir de tais dimensões, a ampliação dos incentivos para a contaminação da lógica curto-prazista em distintas esferas da economia capitalista em nosso tempo, fortalecendo seu processo de financeirização em sentido amplo.

28 Conforme se buscou representar, tais tendências não configuram relações simples ou unidirecionais, o que seria um atentado à complexidade de sua operação, mas ativam-se em múltiplas direções, influenciadas que são por vários fatores de conformação. As mútuas influências entre esses fatores são, portanto, multidirecionais. 


\section{Referências}

BECTOR, R.; MARRATO, A.; SPARROW, C. The hidden alpha in equity trading: steps to increasing returns with the advanced use of information. Oliver Wyman, 2013. Disponivel em: <http:/www.oliverwyman.com/content/dam/oliver-wyman/global/en/files/insights /financial-services/2014/Mar/The\%20Hidden\%20Alpha\%20in\%20Equity\%20Trading. pdf $>$. Acesso em: 14 jan. 2016.

BICCHETTI, D; MAYSTRE, N. The synchronized and long-lasting structural change on commodity markets: evidence from high frequency data. UNCTAD Discussion Papers 208, United Nations Conference on Trade and Development, 2012. Disponível em <http:// vi.unctad.org/devblog/506-high-frequency-trading-contributes-to-deviate-commodityprices-from-fundamentals>. Acesso em: 14 jan. 2016.

BICKMAN, L.; ROG, D. J. Handbook of applied social research methods. Thousand Oaks, Sage, 1997.

BROCK, D. (Ed.). Understanding moore's law: four decades of innovation. Philadelphia: Chemical Heritage Press, 2006.

CHESNAIS, F. A mundialização do capital. São Paulo: Xamã, 1996.

CHESNAIS, F. (Org.). A mundialização financeira: gênese, custos e riscos. São Paulo: Xamã, 1998.

CHESNAIS, F. A teoria do regime de acumulação financeirizado: conteúdo, alcance e interrogações. Economia e Sociedade, Campinas, v. 11, n. 1 (18), p. 1-44, jan./jun. 2002. Disponível em: <http://www.eco.unicamp.br/docdownload/publicacoes/instituto/revistas/ economia-e-sociedade/V11-F1-S18/01-Chesnais.pdf?origin=publication_detail>. Acesso em: 14 jan. 2016.

CHESNAIS, F. (Org.) A finança mundializada: raízes sociais e políticas, configuração, consequências. São Paulo: Boitempo, 2005.

CLARK, A. Natural-born cyborgs: minds, technologies, and the future of human intelligence. New York: Oxford University Press, 2003.

EPSTEIN, G. A. Introduction: Financialization and the Wolrd Economy. Financialization and the World Economy. Northampton, MA: Edward Elgar, 2005, p. 3-17.

GOLUB, A.; KEANE, J. A.; POON, S. H. High frequency trading and mini flash crashes. Working Paper, 28 nov. 2012. Disponível em: <http://arxiv.org/pdf/1211.6667.pdf>. Acesso em: 14 jan. 2016.

HARVEY, D. Condição pós-moderna: uma pesquisa sobre as origens da mudança cultural. São Paulo: Edições Loyola, 1992.

LEWIS, M. Flash Boys: A Wall Street Revolt. New York: WW. Norton\&Company, 2014.

MARX, K. O Capital. v. III, tomo II. São Paulo: Nova Cultural, 1988.

MARX, K. Grundrisse: manuscritos econômicos de 1857-1858. São Paulo: Boitempo, 2011.

MINSKY, H. P. Stabilizing an unstable economy. New Haven: Yale University Press, 1986.

MOLLO, M. L. R. Capital Fictício, autonomia, produção-circulação e crises: precedentes teóricos para o entendimento da crise atual. Revista Economia, Brasília, v. 12, n. 3, p. 475-496. set./dez. 2011. 
PARANÁ, E. A finança digitalizada: capitalismo financeiro e revolução informacional. Florianópolis: Insular, 2016.

PARANÁ, E. A digitalização do mercado de capitais no Brasil: tendências recentes. Boletim de Economia e Política Internacional, BEPI, n. 23, p. 43-71, mai./ago. 2017.

PULITI, P. A Financeirização do Noticiário Econômico (1989-2002). 286p. Tese (Doutorado) - Departamento de Jornalismo e Editoração/Escola de Comunicações e Artes/USP. Universidade de São Paulo. 2009.

SANTOS, M. A aceleração contemporânea: tempo mundo e espaço mundo. Conferência de abertura do Encontro Internacional "O novo mapa do mundo", Departamento de Geografia, Universidade de São Paulo, 1 set 1992. Disponível em: <http://www.redesagrado. com/sagrado-coracao-sp/imagens/comunicado/20129910.pdf>. Acesso em: 14 jan. 2016.

SMITH, R. Is high-frequency trading inducing changes in market microstructure and dynamics?. Cornell University Libery, 2010. Disponível em: <http://arxiv.org/abs/1006.5490>. Acesso em: 14 jan. 2016.

STIGLITZ, J. Information and the change in the paradigm in economics. Nobel Prize Lecture, December 8, 2001. Disponível em: <http://www.nobelprize.org/nobel_prizes/economicsciences/laureates/2001/stiglitz-lecture.pdf >. Acesso em: 14 jan. 2016.

TABB, L. The Value of a Millisecond: Finding the Optimal Speed of a Trading Infrastructure. Tabb Group, Viraf Reporter, April, 2008.

TABB, L.; IATI, R.; SUSSMAN, A. US equity high frequency trading: strategies, sizing and market structure. Tabb Group, 2009. Disponível em <http://www.tabbgroup.com/PublicationDetail.aspx?PublicationID=505>. Acesso em: 14 jan. de 2016.

TEIXEIRA COELHO NETO, J. Semiótica, informação e comunicação. São Paulo: Perspectiva, 1983.

THE GOVERNMENT OFFICE FOR SCIENCE. Foresight: the future of computer trading in financial markets. Final Project Report. London, 2012. Disponível em <http://www.cftc. gov/ucm/groups/public/@aboutcftc/documents/file/tacfuturecomputertrading1012.pdf >. Acesso em 17 jul. 2014.

WEBER, M. A ética protestante e o "espirito" do capitalismo. São Paulo: Companhia das Letras, 2004.

\section{Sobre o autor}

Edemilson Paraná - edemilsonparana@gmail.com

Pseudônimo de Edemilson Cruz Santana Junior, Universidade de Brasília (UnB), Brasília, DF.

\section{Sobre o artigo}

Recebido em 16 de abril de 2016. Aprovado em 12 de setembro de 2016. 